\title{
Prediction of Treatment Response and Diagnosis in Psychiatry
}

\author{
Eduardo Dunayevich, MD \\ University of Cincinnati, College of Medicine, Cincinnati Ohio
}

Follow this and additional works at: https://jdc.jefferson.edu/jeffjpsychiatry

Part of the Psychiatry Commons

Let us know how access to this document benefits you

\author{
Recommended Citation \\ Dunayevich, MD, Eduardo (1995) "Prediction of Treatment Response and Diagnosis in Psychiatry," \\ Jefferson Journal of Psychiatry. Vol. 12 : Iss. 2 , Article 10. \\ DOI: https://doi.org/10.29046/JJP.012.2.006 \\ Available at: https://jdc.jefferson.edu/jeffjpsychiatry/vol12/iss2/10
}

This Article is brought to you for free and open access by the Jefferson Digital Commons. The Jefferson Digital Commons is a service of Thomas Jefferson University's Center for Teaching and Learning (CTL). The Commons is a showcase for Jefferson books and journals, peer-reviewed scholarly publications, unique historical collections from the University archives, and teaching tools. The Jefferson Digital Commons allows researchers and interested readers anywhere in the world to learn about and keep up to date with Jefferson scholarship. This article has been accepted for inclusion in Jefferson Journal of Psychiatry by an authorized administrator of the Jefferson Digital Commons. For more information, please contact: JeffersonDigitalCommons@jefferson.edu. 


\title{
Prediction of Treatment Response and Diagnosis in Psychiatry
}

\author{
Eduardo Dunayevich, M.D.
}

\begin{abstract}
The lack of diagnostic gold standards and the multiplicity of vantage points used to conceptualize mental illness renders psychiatric diagnostic and therapeutic approaches susceptible to individual and cultural biases. Developments in therapeutic approaches have often provided vantage points from which to conceptualize psychopathology. The identification of predictors of treatment response may be a useful element for clinicians to select between multiple treatment tools in an expanding therapeutic armamentarium while fostering refinements in current diagnostic systems.
\end{abstract}

A distinct problem of diagnosis in psychiatry, as compared to other branches of medicine, is the lack of discrete anatomical or physiological correlates of the various diagnostic constructs. Diagnosis in psychiatry is essentially based on observable phenomena (1) and the standard for diagnosis in psychiatry has been two clinicians agreeing on a particular diagnosis for a given patient. Therefore, classifications of mental illness have tended to be influenced by society's beliefs regarding the mind and its illnesses at the time these classifications were created.

An ongoing dilemma in the understanding and classification of psychopathology is the debate about whether entities emerge from a continuum with normal psychological processes or whether they are discrete entities that have a distinct pathophysiology $(1,2)$. This dichotomy mirrors other classic dichotomies, such as nature vs. nurture or biological vs. psychosocial (3). Not surprisingly, classification in psychiatry has at times favored one approach, at others the opposite one. Unfortunately, the relative weight of biological, psychological and social variables and therefore the relevance attributed to each of them in the treatment of mentally ill patients, is far from well demarcated, and clinicians have to rely on their own perceptions (and biases) to generate a model for understanding and diagnosing. Thus, it is common to find that the adherence to a comprehensive biopsychosocial model of psychopathology is more theoretical than practical. In this paper, it is hypothesized that the identification of indicators of treatment response can enhance current diagnostic systems and advance our understanding of psychopathology.

A major tenet of this essay is that what appears to be mainly a theoretical discussion, such as the one that confronts supporters of psychodynamic and biological

Eduardo Dunayevich, M.D. is a 3rd year resident at the University of Cincinnati College of Medicine in the Department of Psychiatry. 
models, is actually derived from developments in therapeutics. Psychoanalytic theory conceptualized mental illness as forming a continuum with normal psychological functioning (4) and its etiology often linked to anomalies of the psychosocial environment, especially during psychological development in childhood (5). This theory evolved at a time in which the main tool available to treat these disorders was the person of the caregiver in charge, and treatment was based on the conduction of a therapeutic relationship in which the vicissitudes of this early psychological development would be replayed and corrected. Biological theories, a counterpart to psychoanalytic theories, also have been spurred by advances in therapeutics $(6,7)$. The discovery of neuroleptics and their specific effects over psychotic symptoms was the cornerstone of the dopamine hypothesis in schizophrenia. The use of lithium salts in psychiatry stimulated discussion over the differential diagnosis of psychotic agitation (8). The development of specific treatments for likely biological conditions, added to the limitations of "theoretically assumed psychodynamic factors" (9) were significant influences in favor of psychiatry being thrust back into the medical and empirical tradition, which emphasizes the recognition of discrete clinical entities, differential diagnosis and differential therapeutics. Specific criteria were developed to identify and validate clinical entities $(10,11)$. The remarkable changes between the second and third versions of the APA's DSM are an expression of the profound changes that took place in the field of classification and diagnosis at that time (12,13).

This renewed medical paradigm, despite being founded on methodologically more solid grounds than the psychosocial one (11) also showed significant limitations. The constructs of schizophrenia and manic depressive illness generated by research diagnostic criteria tend to select a fairly homogeneous group of patients (for the purpose of obtaining samples that most psychiatrists will agree represent the illness in question, and that will allow meaningful research) $(10,14)$ but also leave a significant population outside their boundaries. Despite clear-cut diagnostic criteria, the differentiation between manic depression and schizophrenia has continued to present problems to the clinician, even when family history of psychiatric illness, course, and response to treatment are considered (15). The existence of patients who share phenomenological characteristics of both diagnostic groups regarding presentation and course of illness illustrates the limitations of mental illness categorization $(15,16)$. If the boundaries between manic depressive illness and schizophrenia, two of the most robust, distinct and researched constructs in psychiatry, can still be problematic in some cases, it becomes apparent that the boundaries between other Axis I disorders can become even more challenging $(2,15,17,18)$. Axis II disorders are even more problematic to differentiate from a categorical standpoint $(19,20)$ as well as their boundaries with Axis I conditions $(21,22)$. Already early psychiatrists such as Kraepelin (23) had postulated a continuum between personality disorders and the major psychoses.

Acknowledgment of the ongoing difficulties in the appropriate categorical diagnosis of different clinical entities and the seeming "resistance" of patients to be categorized according to standard criteria has spawned interest in promoting new ways of approaching and understanding clinical phenomena. An "affective spectrum 
disorder" (24) has been postulated to account for the existence of seemingly distinct conditions, which at times are related through comorbidity or phenomenology, that appear at higher frequencies in the families of individuals affected by one of these conditions, and that share response to certain therapeutic interventions. The existence of disabling conditions that do not fit the full criteria for DSM disorders but that still demand attention and treatment has fostered interest in the so called "subsyndromal disorders" $(8,17,25)$ and their relationship to the syndromal ones, with which many times they share responsivity to some therapeutic maneuvers, also pointing to the "soft" boundaries of the diagnostic categories.

Diagnostic systems, like many other theoretical constructs, serve the function of providing a frame, a reference that allows the understanding and structuring of complex phenomena in an orderly fashion. They generate a starting point from which further inquiry, discussion and eventually action, can be undertaken. The clinical situation in psychiatry, with its lack of "gold standards" (1,3) such as reliable diagnostic tests and pathological findings, and in which the reality of the encounter between patient and physician is dependent on how it is structured by the participants, is one in which such frames are highly relied upon to generate "sense" out of its inherent subjectivity. For some, this subjectivity is the raw material that allows the diagnostic and therapeutic activity to proceed (26), even though it may prevent (at least to some extent) the nonparticipants from fully grasping the ongoing process. For others, subjectivity is "noise" that interferes with the tasks of diagnosing and treating an a priori well defined and recognizable syndromal entity. In the end, it appears that the diagnostic process is heavily influenced by the clinician's preexisting theoretical and therapeutic framework. To some extent, the theoretical (and therapeutic) stance of the individual clinician is determining the outcome of the diagnostic process.

In all branches of medicine, a diagnosis is the shorthand by which the current understanding of specific phenomena are codified and how they are to be approached $(10,27)$. It may convey dismay, stigma, relief. It conveys what is to be expected and defines what psychiatrists, as agents of society, are accountable for. Diagnosis is central to medicine as a scientific activity. It defines what the field of application of such scientific knowledge will be. Still, it seems that in the field of mental illness, the process of reaching a diagnosis not only can be held suspect of biases that vary from practitioner to practitioner, but it has also been shown that practitioners that abide by a given set of criteria for diagnosis (such as DSM-III-R) do not necessarily use such criteria appropriately $(11,27)$. And it is also unclear whether the fashion in which diagnostic entities are distinguished from one another is a valid one, as shown by unresolved issues regarding diagnostic boundaries.

Psychiatry's ability to generate valid, reliable diagnosis is at the core of its viability as a medical specialty. It is likely that advances in neuroimaging and neurochemistry will greatly improve our understanding and classification of mental illness. But some of the answers to questions in diagnosis seem to lie in the origins of diagnostic systems. In a complex field such as psychiatry, trying to find a single point of observation or conceptualization to encompass all of its multidimensional features 
is probably illusory, as is trying to compare different vantage points in terms of some objective truth value. As stated by Millon (1):

Clinical processes and events have been described in terms of conditioned habits, reaction formations, cognitive expectancies or neurochemical dysfunctions. These domains cannot be arranged in a hierarchy, with one level viewed as reducible to another. ... The yearning among taxonomists for a neat package of etiologic attributes simply cannot be reconciled with the complex philosophical and methodological issues and the difficult to disentangle networks that shape our mental disorders. It also makes understandable the decision of the DSM-III Task Force to set etiological and course variables aside as clinical grist for its taxonic mills. Turning from the antecedent to the consequent side of the clinical course, logic argues that the nature of a mental disorder must be at least partially revealed by its response to treatment. The data available on this matter, however, provides little that goes beyond broad generalizations. This contrasts with medicine at large, in which a variety of interventions are specific to particular disorders.

With this view in mind, it can be posited that one of the major reasons that the advent of lithium generated so much excitement was because it allowed the identification of a certain group of severely impaired individuals who could have an improved treatment and better outcome. Even though lithium did not become the acid test for diagnosis of manic depression, it is an example of how the responsivity to a certain therapeutic approach (or the lack of it) can impact the whole process of diagnosis and treatment. It has been said that "there are no sicknesses, only sick people" but even if the diagnostic entities of DSM-III-R should be considered as 'prototypical' (2), and the pursuit of more clear-cut discrete categorical entities in psychiatry would reach a standstill, there will still be finite ways of approaching them from a therapeutic standpoint. It makes as much (or even more) sense, to look at psychopathology from the vantage point of finite therapeutic tools, than from the seemingly infinite variations that the clinical presentation may display. Whether there is such a thing as an affective spectrum or not may have great theoretical importance, but for the clinician it is most important because it identifies clinical entities that respond to a certain treatment. And for the researcher, it provides indirect evidence that can lead to direct, confirmatory work $(6,29)$. As in the manic depressive paradigm, as in Freud's neurotic patients, a significant element is the likely response to a particular therapeutic mode. In this context, it follows that an important challenge facing psychiatry at present would be identifying elements that will predict response to particular treatments.

The strength of a science is not only manifested by its explanatory power, but particularly by its predictive power. In this era in which psychiatry is being viewed less and less as primary care and more of a specialty that is to be accessed when less costly and more readily available means have been exhausted, and recruitment of medical students into the field dwindles, part of psychiatry's ability to remain a viable 
specialty may lie in its ability to generate predictions as to what therapeutic tools from our ever broadening armamentarium should be instituted initially, and what steps are to be followed, to ensure the most effective treatment. This applies not only for biological, but also for psychological and social treatments. A substantial amount of research in this field has already generated support for validating diagnostic considerations on the basis of treatment response, as shown by the research in atypical symptoms in depression $(29,30)$, neuropsychological deficits and negative symptoms in schizophrenia $(31,32)$ and cycling characteristics in bipolar disorder (33) between others. Research in non-biological treatments is also yielding promising results for identifying markers of treatment response (34,35). Aside from their pragmatic interest, markers of treatment response can also provide an understanding of the pathophysiology of mental illness that could step beyond the current categorization of psychiatric illness $(24,36)$. There are significant obstacles facing this type of research, such as identifying likely markers and designing adequate prospective studies that can support or rule out a putative marker. Moreover, treatment response is subject to multiple variables that can be difficult to control for. Nevertheless, new light can be shed into how the boundaries between diseases are characterized according to clinical characteristics that differentiate samples of patients who respond to a particular therapeutic maneuver as opposed to the ones who do not. In this context, the increasing use of scales and questionnaires in clinical practice, borrowed many times from research applications, can serve as attempts to obtain structured information and span the gap between the subjective reality of the clinical interview, with its wealth of interpersonal data, and the possible objective disturbances of brain structure and function. They can also be the means through which prospective data can be gathered to characterize predictors of treatment response.

The determination of the characteristics of subgroups of patients responsive to specific therapeutic approaches might provide psychiatry with more data to help generate consistent and meaningful diagnostic systems that will span the dichotomy between categorical and continuous conceptualizations of mental illness, increasing psychiatry's explanatory and predictive powers. It may also help psychiatry maintain quality care in an era of managed resources.

\section{REFERENCES}

1. Millon T: Classification in psychopathology: Rationale, alternatives, and standards. Journal of Abnormal Psychology 1991; 100:245-261

2. Carson RC: Dilemmas in the pathway of the DSM-IV. Journal of Abnormal Psychology 1991; 100:302-307

3. Blashfield RK, Livesley JW: Metaphorical analysis of psychiatric classification as a psychological test. Journal of Abnormal Psychology 1991; 100:262-270

4. Freud S: The psychopathology of everyday life. Standard Edition 1960; 6:1-279, London, Hogarth Press

5. Gabbard GO: Psychodynamic Psychiatry in Clinical Practice 1990. American Psychiatric Press, Inc. 
6. Barr LC, Goodman WK, Price LH, et al: The serotonin hypothesis of obsessive compulsive disorder: Implications of pharmacologic challenges. J Clin Psychiatry; 53 suppl: 17-28

7. De Lecuona JM, Joseph KS, Iqbal N, et al: The dopamine hypothesis of schizophrenia revisited. Psychiatric Annals 1993; 23:179-185

8. Wing JK, Cooper JE, Sartorius N: The measurement and classification of psychiatric symptoms. Cambridge, Cambridge University Press, 1974

9. Morey LC: Classification of mental disorder as a collection of hypothetical constructs. Journal of Abnormal Psychology 1991; 100:289-293

10. Feighner JP, Robbins E, Guze SB, et al: Diagnostic criteria for use in psychiatric research. Arch Gen Psychiatry 1972; 26:57-63

11. Widiger TA, Frances AJ, Pincus HA, et al: Toward an empirical classification for the DSM-IV. Journal of Abnormal Psychology 1991; 100:280-288

12. American Psychiatric Association: Diagnostic and statistical manual of mental disorders, second edition. Washington, DC, 1968

13. American Psychiatric Association: Diagnostic and statistical manual of mental disorders, third edition. Washington, DC, 1980

14. Boyd JH, Burke JD, Gruenberg E, et al: Exclusion criteria of DSM-III. Arch Gen Psychiatry 1984; 41:983-989

15. Blacker D, Tsuang MT: Contested boundaries of Bipolar Disorder and the limits of categorical diagnosis in psychiatry. Am J Psychiatry 1992; 149:1473-1483

16. Brockington IF, Meltzer HY: The nosology of schizoaffective psychosis. Psychiatric Developments 1983; 1:317-338

17. Liebowitz MR, Hollander E, Schneier F, et al: Anxiety and depression: Discrete diagnostic entities? J Clin Psychopharm 1990; 10 suppl:61S-66S

18. Boulenger JP, Lavallee YJ: Mixed anxiety and depression: Diagnostic issues. J Clin Psychiatry 1993; 54 suppl:3-8

19. Frances A: The DSM-III personality disorders section: A commentary. Am J Psychiatry 1980; 137:1050-1054

20. Livesley JW, Schroeder ML, Jackson DN, et al: Categorical distinctions in the study of personality disorder: Implications for classification. Journal of Abnormal Psychology 1994; 103:6-17

21. Akiskal H, Hirschfeld RMA, Yerevanian BI: The relationship of personality to affective disordes. Arch Gen Psychiatry 1983; 40:801-810

22. Widiger TA, Shea T: Differentiation of axis I and axis II disorders. Journal of Abnormal Psychology 1991; 100:399-406

23. Kraepelin E: Clinical Psychiatry. New York, Macmillan, 1907

24. Hudson JI, Pope HG: Affective spectrum disorder: Does antidepressant response identify a family of disorders with a common pathophysiology? Am J Psychiatry 1990; 147:552-564

25. Aronson TA: Atypical anxiety disorder: A descriptive study. Compr Psychiatry 1990; $31: 152-161$

26. Ornstein A, Ornstein PH: Empathy and the therapeutic dialogue. Expanded and updated version of a paper first presented at the Fifth Annual Psychotherapy Symposium on "Psychotherapy: The Therapeutic Dialogue." Harvard University, The Cambridge Hospital, Boston, Massachusetts, June 28-30, 1984

27. First MB: Computer-assisted assessment of DSM-III-R diagnoses. Psychiatric Annals 1994; 24:25-29

28. American Psychiatric Association: Diagnostic and statistical manual of mental disorders, third edition-revised. Washington, D.C., 1987 
29. Liebowitz MR, Quitkin FM, Stewart JW, et al: Psychopharmacologic validation of atypical depression. J Clin Psychiatry 1984; 45 (7 Pt 2):22-25

30. Quitkin FM, Harrison W, Liebowitz M, et al: Defining the boundaries of atypical depression. J Clin Psychiatry 1984; 45 (7 Pt. 2):19-21

31. Convit A, Volavka J, Czobor P, et al: Effect of subtle neurological dysfunction on response to haloperidol treatment of schizophrenia. Am J Psychiatry 1994; 151:49-56

32. Goldman RS, Axelrod BN, Tandon R, et al: Neuropsychological prediction of treatment efficacy and one-year outcome in schizophrenia. Psychopathology 1993; 26:122-126

33. Keck PE, McElroy SL: Current perspectives on treatment of bipolar disorder with lithium. Psychiatric Annals 1993; 23:64-69

34. Luborsky L, Crits-Christoph P, Mintz J, et al: Who will benefit from psychotherapy. New York, Basic Books Inc: 269-286, 1988

35. Moras K, Strupp H: Pretherapy interpersonal relations, patients' alliance, and outcome in Brief Therapy. Arch Gen Psychiatry 1982; 39:405-409

36. McElroy SL, Hudson JI, Phillips KA, et al: Clinical and theoretical implications of a possible link between obsessive-compulsive and impulse control disorders. Depression 1993; 1:121-132 